\title{
Eficácia do antibiótico profilático intraósseo versus endovenoso em cirurgias do joelho em porcos: Estudo experimental*
}

\section{Effectiveness of Prophylactic Intraosseous Antibiotic versus Intravenous Antibiotic in Knee Surgeries in Pigs: An Experimental Study}

\author{
Carlos Augusto de Mattos ${ }^{1}$ Nina Razzo Pereira dos Santos ${ }^{10} \quad$ Mariana de Oliveira Cyrino ${ }^{1}$ \\ Laura Credidio $^{2}$ Natália Silveira Virgilli ${ }^{3}$ Joaquim Simões Neto ${ }^{4}$
}

${ }^{1}$ Serviço de Ortopedia e Traumatologia, Hospital e Maternidade Celso Pierro, Pontifícia Universidade Católica de Campinas, Campinas, SP, Brasil

2 Universidade Estadual de Campinas, Campinas, SP, Brasil

3 Faculdade de Ciências Médicas, Pontifícia Universidade Católica de Campinas, Campinas, SP, Brasil

${ }^{4}$ Serviço de Cirurgia de Urgência de Trauma, Hospital e Maternidade Celso Pierro, Pontifícia Universidade Católica de Campinas,

Campinas, SP, Brasil

\begin{abstract}
Endereço para correspondência Nina Razzo Pereira dos Santos, Serviço de Ortopedia e Traumatologia, Hospital e Maternidade Celso Pierro, Pontifícia Universidade Católica de Campinas, Campinas, SP, Brasil (e-mail: ninarps@hotmail.com).
\end{abstract}

Rev Bras Ortop 2019;54:556-563.

\begin{abstract}
Resumo
Palavras-chave

- agentes antibacterianos

- profilaxia

- artroplastia

- infecção

- animais

- suínos

Objetivo Demonstrar, em 36 porcos usados como modelos vivos, que o acesso intraósseo (IO) é mais eficaz em comparação com o acesso endovenoso (EV) na administração de antibiótico profilático em cirurgias na articulação do joelho.

Materiais e Métodos Foram coletadas, analisadas e comparadas amostras de pele, tecido subcutâneo, cartilagem e osso, após administração de antibiótico profilático EV e IO em grupos diferentes.

Resultado A comparação entre os grupos 10 e EV indicou que no grupo IO houve maior concentração de antibiótico profilático na pele $(p=0,049)$, na cartilagem $(p=0,018)$ e no osso $(p=0,002)$, na análise das primeiras 24 horas após 30 minutos de infusão.

Conclusão Visto que as complicações dessa prática são raras, o uso dessa via pode ser uma opção para a diminuição do risco de infecção do sítio cirúrgico nas cirurgias ortopédicas, pois leva à diminuição da morbimortalidade e dos gastos hospitalares com reabordagens ou com tempo prolongado de internação. Contudo, são necessários mais pesquisas e novos estudos experimentais em seres humanos, dado que está comprovada a eficácia do método em porcos.
\end{abstract}

\footnotetext{
* Trabalho desenvolvido no Hospital da Pontifícia Universidade Católica de Campinas, Campinas, SP, Brasil. Publicado Originalmente por Elsevier Editora Ltda.
}

recebido

29 de Agosto de 2017

aceito

22 de Dezembro de 2017
DOI https://doi.org/

10.1016/j.rbo.2017.12.011. ISSN $0102-3616$
Copyright $\odot 2019$ by Sociedade Brasileira License terms de Ortopedia e Traumatologia. Published by Thieme Revnter Publicações Ltda, Rio de Janeiro, Brazil 


\section{Abstract}

\section{Keywords}

- antibacterial agents

- prophylaxis

- arthroplasty

- infection

- animals

- swine
Objective To demonstrate that the intraosseous (IO) access is more effective compared with the intravenous (IV) access for prophylactic antibiotic administration in knee joint surgeries, using 36 pigs as live models.

Materials and Methods Skin, subcutaneous tissue, cartilage, and bone samples were collected, analyzed and compared after the administration of IV or IO antibiotic in different groups.

Results When comparing the 10 and IV groups, the 10 group showed a higher concentration of prophylactic antibiotic in the skin $(p=0.049)$, cartilage $(p=0.018)$, and bone $(p=0.002)$, in the analysis of the first 24 hours after 30 minutes of infusion. Conclusion Since complications regarding this practice are rare, the use of this pathway may be an alternative to reduce the risk of surgical site infection in orthopedic surgeries, leading to a decrease in morbidity and mortality and in hospital expenses with readmission or prolonged hospitalization time. However, further research and further experimental studies in humans are required, as the effectiveness of the method in pigs has been proven.

\section{Introdução}

A infecção no sítio cirúrgico é uma causa significativa de morbimortalidade nas cirurgias articulares do joelho, e tem um impacto indireto na economia do país. ${ }^{1}$ Pacientes infectados têm mais chance de óbito, de necessitar de cuidados intensivos, e de precisar de reabordagem. Enfermarias ortopédicas são classificadas como locais de alto risco para tal complicação, principalmente em pacientes submetidos a artroplastias. ${ }^{2}$ Contudo, a administração do antibiótico profilático tem causado a diminuição das taxas de contaminação e de infecção, sendo o foco de muitas pesquisas atuais. ${ }^{1,3}$

As bactérias mais comuns causadoras de contaminação e subsequente infecção nas artroplastias totais de joelho são os Staphylococcus aureus e estafilococos coagulase-negativos (ECNs). ${ }^{3-5} \mathrm{~A}$ administração sistêmica do antibiótico de primeira geração das cefalosporinas e da vancomicina tem sido a recomendação mais aceita na profilaxia. As cefalosporinas têm um espectro de atividade contra ECNs, $S$. aureus sensíveis a meticilina (SASM) e algumas bactérias gram-negativas, enquanto a vancomicina é ativa para $S$. aureus resistente a meticilina (SARM). ${ }^{3}$

Para que o antibiótico profilático seja eficaz, a sua concentração no tecido deve exceder a concentração mínima inibitória (CMI) do organismo comumente causador da infecção em um período entre a incisão e o fechamento da ferida. ${ }^{1,4,6}$ Estudos recentes têm questionado se a concentração de antibiótico alcançada no tecido com a administração EV como profilaxia é adequada para a atividade bactericida. ${ }^{3}$
Young et $\mathrm{al}^{7}$ demonstraram que se pode alcançar maior concentração no tecido com a administração regional intraóssea (ARIO) de antibiótico profilático em pacientes submetidos a cirurgias no joelho, após a colocação do torniquete e antes da incisão na pele. ${ }^{1,3,7} \mathrm{Um}$ estudo ${ }^{3}$ randomizado com pacientes com prótese total de joelho comparou a ARIO com a administração EV, e demonstrou que a ARIO alcançou concentrações teciduais dez vezes maiores do que a administração $\operatorname{IV}^{3,7,8}$ (-Tabela 1).

Considerando o maior risco de complicações nos pacientes infectados, é fundamental o desenvolvimento de medidas mais eficazes que auxiliem na prevenção delas. Assim, o presente estudo buscou caracterizar, do ponto de vista prático e quantitativo, o uso do acesso IO regional para que se pudesse obter maior concentração no tecido durante esses tipos de cirurgias.

O objetivo do presente estudo é demonstrar que o acesso IO apresenta maior concentração local de antibiótico profilático em cirurgias no joelho suíno comparado com a administração EV.

\section{Materiais e Métodos}

Este estudo foi feito na Disciplina de Bases em Técnicas Operatórias no biotério, e foi aprovado pelo Comitê de Ética de Uso de Animais, de acordo com a resolução normativa no 007/12 (protocolo de aprovação no 030/2016). O modelo animal objeto do estudo foi desenvolvido com 36 porcos (Sus scrofa domesticus), machos ou fêmeas, com 3 meses de idade e peso aproximado de $16 \mathrm{~kg}$.

Tabela 1 Concentração de antibiótico por tecido (Wellman ${ }^{3}$ )

\begin{tabular}{|l|l|l|l|l|l|}
\hline Tipo de tecido & $\begin{array}{l}\mathbf{2 5 0} \mathrm{mg} \text { de ARIO } \\
\text { de vancomicina }\end{array}$ & $\begin{array}{l}500 \mathrm{mg} \text { de ARIO } \\
\text { de vancomicina }\end{array}$ & $\begin{array}{l}\mathbf{1} \mathrm{g} \text { de } \\
\text { vancomicina EV }\end{array}$ & $\begin{array}{l}\mathbf{1} \mathrm{g} \text { de ARIO } \\
\text { de cefazolina }\end{array}$ & $\begin{array}{l}\mathbf{1} \mathrm{g} \text { de } \\
\text { cefazolina EV }\end{array}$ \\
\hline Gordura subcutânea (ug/g) & 14 & 44 & 3,2 & 186 & 11 \\
\hline Osso (ug/g) & 16 & 38 & 4 & 130 & 11 \\
\hline
\end{tabular}

Abreviaturas: ARIO, administração regional intraóssea; EV, endovenoso. 
Os animais destinados ao estudo foram alimentados com ração Presuntina e água potável (fornecida pela Sociedade de Abastecimento de Água e Saneamento S/A, Sanasa) sob demanda, e permaneceram em ambiente preparado (baias) individualizado. Foram rigorosamente adotadas e seguidas as recomendações e normatizações prescritas pelo Comitê de Ética para uso e proteção de animais em experimentos científicos. Todos foram sacrificados imediatamente após os procedimentos, também de acordo com as recomendações do Comitê de Ética.

Para os procedimentos experimentais, foram formados 3 grupos com 12 porcos, todos submetidos a acesso venoso periférico, anestesia geral e intubação orotraqueal, e, em seguida, antissepsia do(s) membro(s) abordado com clorexidina aquosa a $2 \%$. Em todos os porcos, foram feitas coletas de material da região do joelho em dois momentos. Em cada coleta foram retiradas duas amostras de pele do joelho, duas de tecido subcutâneo do joelho, duas de cartilagem do planalto tibial, e duas de osso da extremidade proximal da tíbia. Tais amostras seguiram o mesmo padrão para retirada (mesmos equipamentos, tamanho semelhante, mesmos locais de retirada, e mesma equipe). Além disso, foram usados instrumentais limpos com clorexidina, e a equipe usou roupas cirúrgicas limpas e luvas estéreis. No primeiro grupo, o grupo de controle (GC), foi administrado apenas soro fisiológico a $0,9 \%$ pelo acesso venoso periférico (na orelha do animal). A primeira coleta foi feita 30 minutos após o término da infusão, e a segunda, após uma hora do término da infusão. No segundo, o grupo intraósseo (GIO), foi colocado torniquete no membro inferior direito (na coxa) de cada animal, e, depois, administrada uma ampola de cefazolina $2 \mathrm{~g}$ por via IO, diluída em $20 \mathrm{~mL}$ de soro fisiológico a $0,9 \%$, por meio do dispositivo NIO Pediatric (PerSys Medical, Houston, TX, EUA) na região medial do planalto tibial. A primeira coleta foi feita 30 minutos após a infusão do antibiótico, e a segunda amostra foi coletada após uma hora do término da infusão. Para que se fizesse uma análise melhor, um terceiro grupo (grupo intraósseo contralateral, GIOCL) foi criado, com amostras coletadas ao mesmo tempo em que o GIO, porém no membro contralateral, em que não havia sido administrada antibioticoterapia IO. No quarto grupo (grupo intravenoso, GIV), foi administrada uma ampola de cefazolina $2 \mathrm{~g}$ por via $\mathrm{EV}$, diluída em 250 mililitros de soro fisiológico a $0,9 \%$. O tempo transcorrido entre o início e o término da infusão foi, em média, de 20 minutos. Após 30 minutos do término da infusão do antibiótico, foi feita a primeira coleta de material, e a segunda, 1 hora após o término da infusão (-Fig. 1). Para as análises, foram usadas placas de Ágar Sal Manitol, que foram incubadas com S. aureus na diluição de 4:1 (4 partes de soro para 1 parte de bactéria), e aplicou-se a diluição com swab estéril. Logo após a semeadura da placa, amostras dos tecidos foram inseridas nela, e incubadas a $37^{\circ} \mathrm{C}$. Após 24 horas de incubação, foi feita a primeira análise dos halos. Após a primeira análise, as amostras tornaram a ser incubadas por mais 24 horas para a segunda leitura. $^{9-11}$ A formação de um halo vermelho nas placas significa que as bactérias não cresceram, ou seja, a medicação presente no tecido matou as bactérias que estavam naquele local (-Fig. 2).

\section{Resultados}

Os resultados foram obtidos por meio da multiplicação do diâmetro maior com o diâmetro menor, em centímetros, do halo vermelho formado em torno de cada tecido (-Fig. $\mathbf{3}$ ).

O teste estatístico aplicado foi o de Mann-Whitney, teste não paramétrico com amostras independentes. Foram analisadas 240 amostras ( 5 foram descartadas por contaminação das placas), que foram distribuídas da seguinte forma: 59 no GC; 60 no GIO; 56 no GIOCL; e 60 no GIV. De cada grupo foram retiradas duas amostras de pele: 1 de tecido subcutâneo, 1 de cartilagem e 1 de osso após 30 minutos de infusão de cefazolina, e outra de cada um dos mesmos tecidos após 1 hora.

Todas as amostras foram medidas e pesadas para ver se não tinham diferença de tamanho ou peso que poderia influenciar no tamanho do halo (amostras maiores teriam halos maiores). Os tamanhos das amostras, com leitura após 24 e 48 horas ( $p=0,715$ e 0,977 , respectivamente), e os seus pesos, com leitura após 24 e 48 horas $(p=0,171$ e 0,623, respectivamente), quando comparados entre os grupos, não revelaram diferença estatística; portanto, provou-se que as amostras eram homogêneas (-Fig. 4).
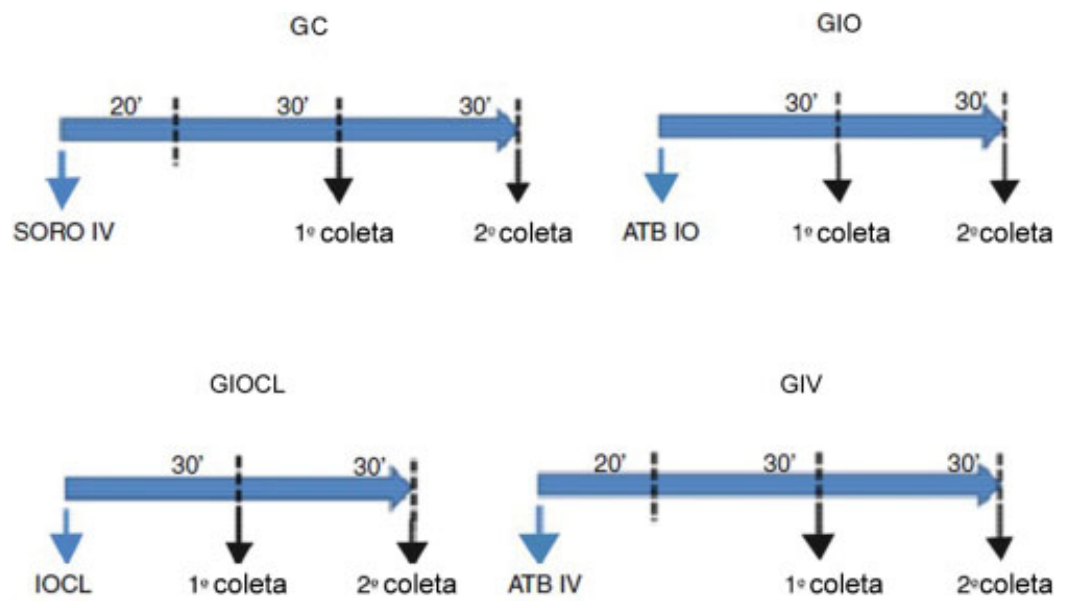

Fig. 1 Esquema representativo do fluxograma das coletas. 

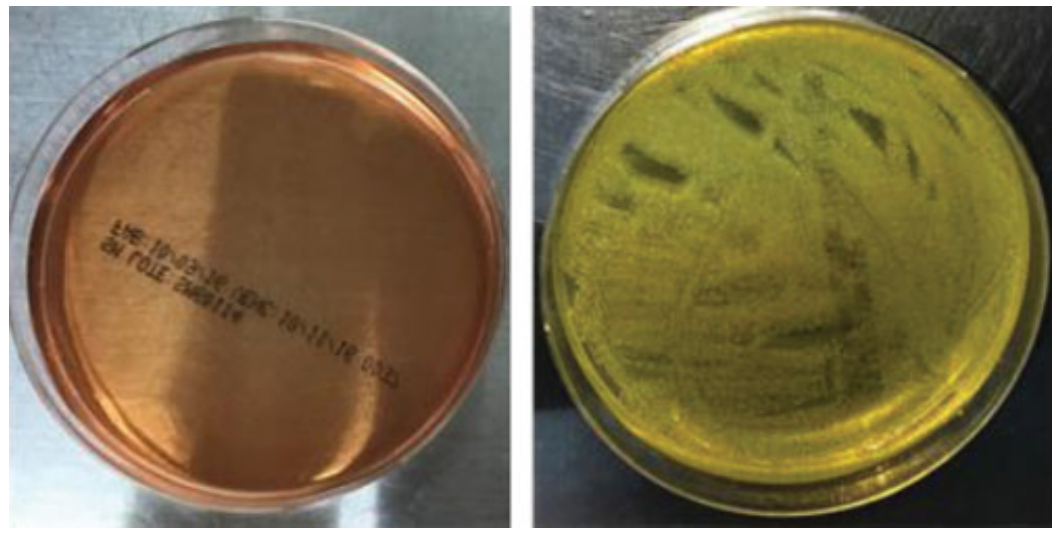

Fig. 2 Placa de sal manitol sem e com Staphylococcus aureus respectivamente.

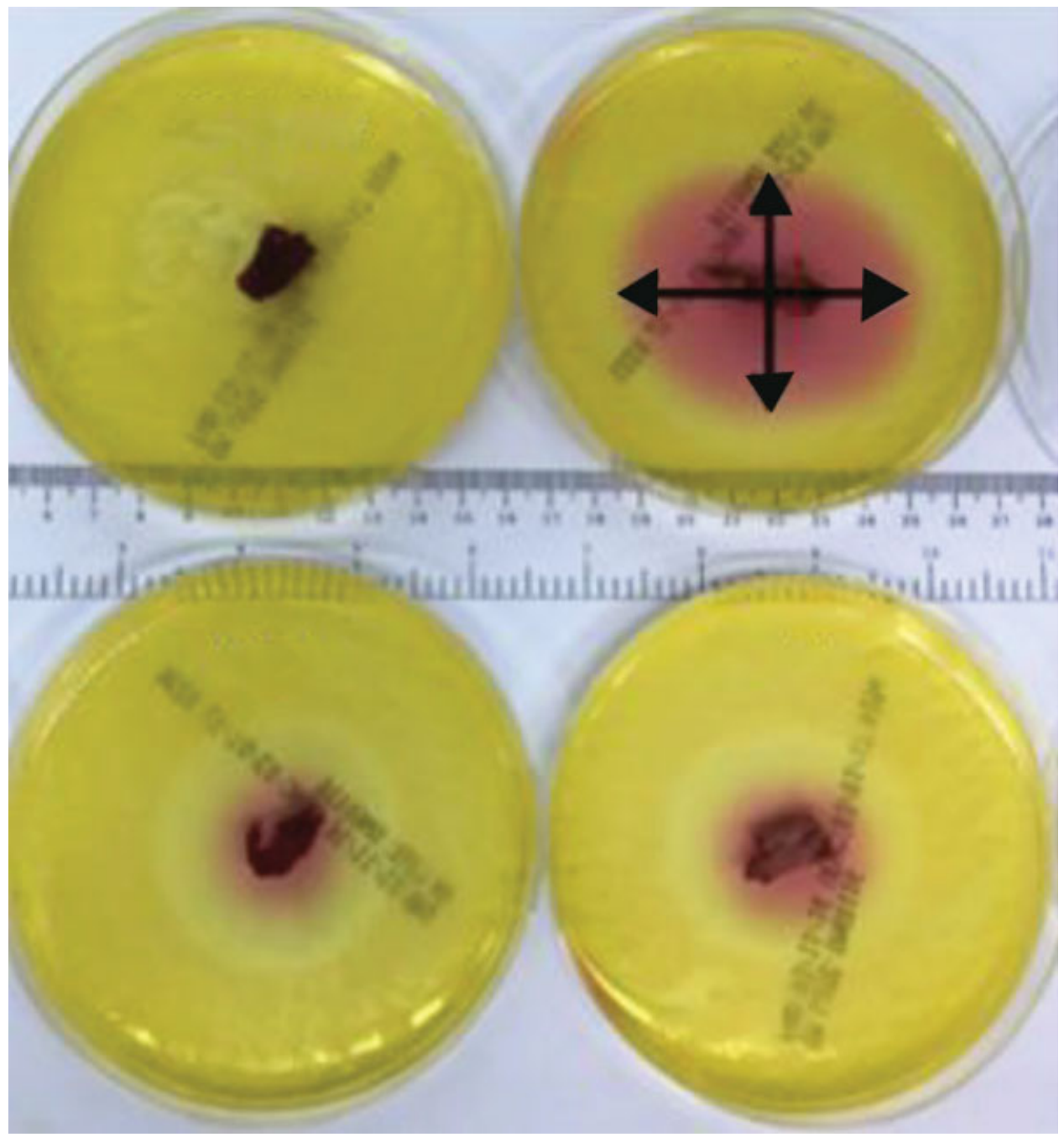

Fig. 3 Cultura de tecido ósseo após 30 minutos de administração da cefazolina em cultura de 24 horas.

A análise do tamanho dos halos, com a soma de todos os tecidos juntos, mostrou que o GIO obteve a maior média $(25,57 \mathrm{~cm})$, e a menor média foi do GC $(1,81 \mathrm{~cm})$. Na análise de todos os tecidos juntos, o GIO matou maior número de bactérias em volta do tecido do que todos os outros grupos. As análises estatísticas das médias dos grupos em relação aos tipos de tecidos analisados estão ilustradas na - Tabela 2 e na - Figura 4.

Para saber em qual tecido o valor de $p$ foi significativo, fizemos a comparação individual por grupo e por tecido. Não ocorreu significância estatística quando comparados o GIOCL e o GIV; todos os valores de $p$, quando comparados 


\begin{tabular}{|lll}
\hline Controle & $=10 \quad$ IOCL & IV
\end{tabular}

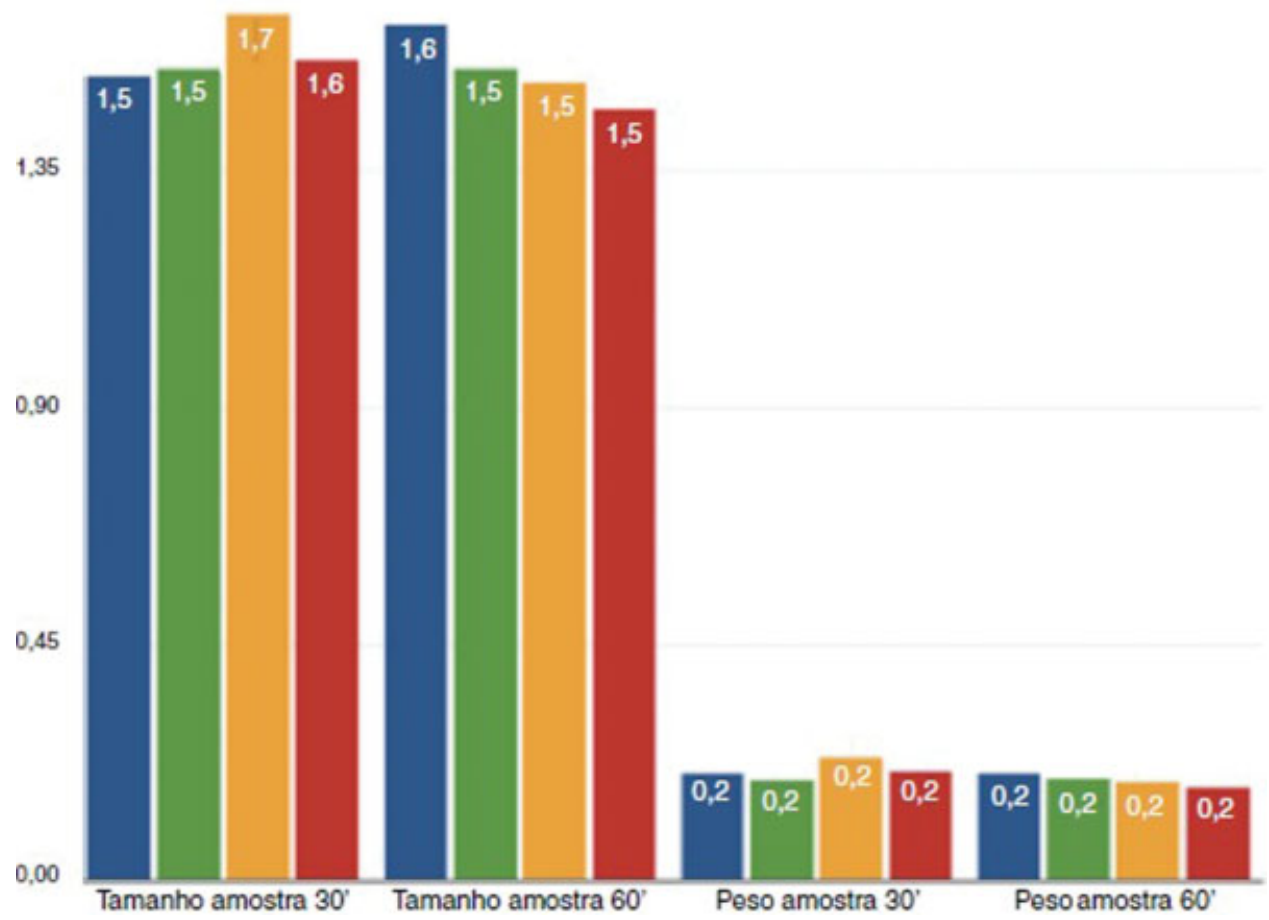

Fig. 4 Média por grupo referente ao tamanho e peso das amostras.

Tabela 2 Análise do GIO em relação ao GIOCL e ao GIV

\begin{tabular}{|l|l|}
\hline Grupo & Valor de $p$ \\
\hline Tempo $24 \mathrm{~h} / 30 \mathrm{~min}$ & \\
\hline $\mathrm{GIO} \times \mathrm{GIOCL}$ & 0,000000297 \\
\hline $\mathrm{GIO} \times \mathrm{GIV}$ & 0,0000453 \\
\hline Tempo $24 \mathrm{~h} / 1 \mathrm{~h}$ & \\
\hline $\mathrm{GIO} \times \mathrm{GIOCL}$ & 0,00000182 \\
\hline $\mathrm{GIO} \times \mathrm{GIV}$ & 0,0003722 \\
\hline Tempo $48 \mathrm{~h} / 30 \mathrm{~min}$ & \\
\hline $\mathrm{GIO} \times \mathrm{GIOCL}$ & 0,0042 \\
\hline $\mathrm{GIO} \times \mathrm{GIV}$ & 0,005 \\
\hline Tempo $48 \mathrm{~h} / 1 \mathrm{~h}$ & \\
\hline $\mathrm{GIO} \times \mathrm{GIOCL}$ & 0,04 \\
\hline $\mathrm{GIO} \times \mathrm{GIV}$ & 0,047 \\
\hline
\end{tabular}

Abreviaturas: GIO, grupo intraósseo; GIOCL, grupo intraósseo contralateral; GIV, grupo intravenoso.

com os tecidos individualmente, foram maiores do que 0,05. Ou seja, a medicação venosa e o joelho contralateral se comportaram da mesma forma. O GC só formou o halo nos tecidos da pele devido à assepsia pré-operatória.

O GIO, quando comparado aos outros grupos, obteve resultado estatístico significativo em todas as coletas e em todos os tempos (-Tabela 2); o halo formado pelo GIO foi maior em todas as amostras.

Na comparação por tipo de tecido do GIO com o GIOCL, o GIO se mostrou superior nas primeiras 24 horas da coleta de
Tabela 3 Análise do GIO e do GIOCL em relação aos tecidos

\begin{tabular}{|c|c|c|}
\hline GIO x GIOCL & Tecido & Valor de $p$ \\
\hline \multirow[t]{3}{*}{$\begin{array}{l}\text { Tempo } \\
24 \text { h/30 min }\end{array}$} & $\begin{array}{l}\text { Pele } \\
\text { Subcutâneo }\end{array}$ & $\begin{array}{l}0,029 \\
0,016\end{array}$ \\
\hline & Cartilagem & 0,004 \\
\hline & Osso & 0,002 \\
\hline \multirow[t]{3}{*}{$\begin{array}{l}\text { Tempo } \\
24 \mathrm{~h} / 1 \mathrm{~h}\end{array}$} & $\begin{array}{l}\text { Pele } \\
\text { Subcutâneo }\end{array}$ & $\begin{array}{l}0,052 \\
0,017\end{array}$ \\
\hline & Cartilagem & 0,002 \\
\hline & Osso & 0,002 \\
\hline \multirow[t]{3}{*}{$\begin{array}{l}\text { Tempo } \\
48 \text { h/30 min }\end{array}$} & $\begin{array}{l}\text { Pele } \\
\text { Subcutâneo }\end{array}$ & $\begin{array}{l}0,096 \\
0,476\end{array}$ \\
\hline & Cartilagem & 0,774 \\
\hline & Osso & 0,008 \\
\hline \multirow[t]{3}{*}{$\begin{array}{l}\text { Tempo } \\
48 \mathrm{~h} / 1 \mathrm{~h}\end{array}$} & $\begin{array}{l}\text { Pele } \\
\text { Subcutâneo }\end{array}$ & $\begin{array}{l}0,275 \\
0,655\end{array}$ \\
\hline & Cartilagem & 0,678 \\
\hline & Osso & 0,034 \\
\hline
\end{tabular}

Abreviaturas: GIO, grupo intraósseo; GIOCL, grupo intraósseo contralateral.

30 minutos na pele $(p=0,029)$, e, no tecido subcutâneo, também se mostrou superior nas primeiras 24 horas, tanto na coleta de 30 minutos quanto na de 1 hora $(p=0,016$ e 0,017 , respectivamente). Na cartilagem, nas primeiras 24 horas, tanto na coleta de 30 minutos quanto na de 1 hora, também foi significante estatisticamente ( $p=0,004$ e 0,002 respectivamente). Quando comparado o tecido ósseo com 
Eficácia do antibiótico profilático intraósseo versus endovenoso em cirurgias do joelho em porcos Mattos et al. 561

Tabela 4 Comparação das médias entre o GIO e o GIOCL

\begin{tabular}{|l|l|l|l|l|}
\hline Tecido & $\begin{array}{l}\text { Amostra } \\
\mathbf{2 4} \mathrm{h} / \\
\mathbf{3 0} \mathrm{min}\end{array}$ & $\begin{array}{l}\text { Amostra } \\
\mathbf{2 4} \mathrm{h} / \\
\mathbf{6 0} \mathrm{min}\end{array}$ & $\begin{array}{l}\text { Amostra } \\
\mathbf{4 8} \mathrm{h} / \\
\mathbf{3 0} \mathrm{min}\end{array}$ & $\begin{array}{l}\text { Amostra } \\
\mathbf{4 8} \mathrm{h} / \\
\mathbf{6 0} \mathrm{min}\end{array}$ \\
\hline GIO pele & 30,15 & 29,29 & 5,02 & 4,03 \\
\hline $\begin{array}{l}\text { GIO } \\
\text { subcutâneo }\end{array}$ & 24,93 & 25,56 & 3,78 & 3,09 \\
\hline $\begin{array}{l}\text { GIO } \\
\text { cartilagem }\end{array}$ & 19,54 & 20,60 & 1,36 & 2,20 \\
\hline GIO osso & 27,65 & 20,67 & 4,63 & 2,73 \\
\hline GIOCL pele & 18,85 & 18,94 & 2,55 & 3,15 \\
\hline $\begin{array}{l}\text { GIOCL } \\
\text { subcutâneo }\end{array}$ & 15,31 & 15,45 & 3,68 & 2,39 \\
\hline $\begin{array}{l}\text { GIOCL } \\
\text { cartilagem }\end{array}$ & 11,26 & 9,01 & 1,99 & 1,62 \\
\hline GIOCL osso & 11,61 & 7,62 & 2,28 & 0,37 \\
\hline
\end{tabular}

Abreviaturas: GIO, grupo intraósseo; GIOCL, grupo intraósseo contralateral.

os outros tecidos, em todos os tempos, o GIO foi superior (-Tabelas 3 e 4). Na análise dos valores das tabelas, observamos que em ambas as coletas (30 minutos e 1 hora), após medicação IO, o torniquete manteve a medicação mais concentrada no joelho de interesse, ou seja, a medicação estava mais concentrada nesses tecidos, matou maior número de bactérias, e aumentou o halo formado em volta. Após 48 horas, a concentração do antibiótico diminui, as bactérias conseguem crescer, e chegam próximo ao tecido; porém, o tecido ósseo foi o único estatisticamente significativo em ambas as coletas $(p=0,008$ erro padrão $[E P]=0,034)$. Na comparação por tipo de tecido do GIO com o GIV, GIO se mostrou superior nas primeiras 24 horas da coleta de 30 minutos na pele, com $p=0,049$, e, no tecido subcutâneo, não houve significância estatística entre os grupos. Na cartilagem, nas primeiras 24 horas, tanto na coleta de 30 minutos quanto na de 1 hora, foi significante estatisticamente $(p=0,018$ e 0,014 , respectivamente). Quando comparado o tecido ósseo, nos três primeiros tempos, o GIO foi superior, porém, na segunda coleta, com incubação de 48 horas, não ocorreu significância estatística (-Tabela 5). Observamos que o halo do tecido ósseo no GIO foi maior quando comparado com todos os grupos. Isso significa que a concentração de antibiótico foi maior nesse tecido, matou as bactérias em volta dele, e aumentou o tamanho do halo, tanto na coleta após 30 minutos da infusão quanto após 1 hora (-Fig. 5).

\section{Discussão}

Foi comprovado que os antibióticos profiiláticos reduzem as taxas de infecção nas artroplastias, ${ }^{1,7}$ e, para serem eficazes, devem ter concentrações teciduais adequadas no local operatório desde a incisão até o fechamento. ${ }^{12,13}$ Embora antibióticos, como os aminoglicósidos e as fliuoroquinolonas, sejam dependentes da concentração, para os antibióticos b-lactâmicos, tais como a cefazolina, o fator mais importante é o tempo
Tabela 5 Análise do GIO e do GIV em relação aos tecidos

\begin{tabular}{|l|l|}
\hline GIO x GIV & Valor de $p$ \\
\hline Tempo 24 h/30 min & \\
\hline Pele & 0,049 \\
\hline Subcutâneo & 0,178 \\
\hline Cartilagem & 0,018 \\
\hline Osso & 0,002 \\
\hline Tempo 24 h/1 $h$ & \\
\hline Pele & 0,074 \\
\hline Subcutâneo & 0,056 \\
\hline Cartilagem & 0,014 \\
\hline Osso & 0,038 \\
\hline Tempo 48 $h / 30$ min & \\
\hline Pele & 0,174 \\
\hline Subcutâneo & 0,440 \\
\hline Cartilagem & 0,678 \\
\hline Osso & 0,006 \\
\hline Tempo 48 $h / 1 h$ & \\
\hline Pele & 0,275 \\
\hline Subcutâneo & 0,632 \\
\hline Cartilagem & 0,587 \\
\hline Osso & 0,087 \\
\hline
\end{tabular}

Abreviaturas: GIO, grupo intraósseo; GIV, grupo intravenoso.

acima da CIM. À medida que a resistência aos antibióticos aumenta, a administração sistêmica das cefalosporinas pode já não proporcionar concentrações adequadas nos tecidos, enquanto ARIO atinge concentrações teciduais muito mais elevadas. ${ }^{14}$ Há muitas evidências de que a antibioticoterapia profilática nas cirurgias osteomusculares, especificamente neste caso, no joelho, feita por via IO regional, tem se mostrado mais eficaz do que quando feita por via EV, como é feito convencionalmente no Brasil.

Este estudo experimental mostrou que a ARIO proporcionou maior inibição bacteriana, provavelmente por ter maior concentração da cefazolina, presente nos tecidos locais, do que a mesma dose do antibiótico administrada sistemicamente, em modelo suíno, demonstrado por meio do crescimento de estafilococos nas placas de Petri; e as placas de IO impediram, em maior quantidade, o crescimento do S. aureus. Assim, foi deduzido que a concentração do antibiótico encontrada nos tecidos foi superior no GIO em relação ao GIV e ao GIOCL, como observado também por Young et al. ${ }^{1}$

Em todos os tecidos estudados, a concentração do antibiótico no grupo que recebeu a ARIO foi superior quando comparado com o GC. Na pele, as concentrações foram mais elevadas nas amostras coletadas aos 30 minutos da administração da medicação, sendo o principal momento em que é necessário o pico de concentração nesse local - incisão da pele no início do procedimento. No tecido subcutâneo, na cartilagem e no osso, o crescimento bacteriano se manteve 


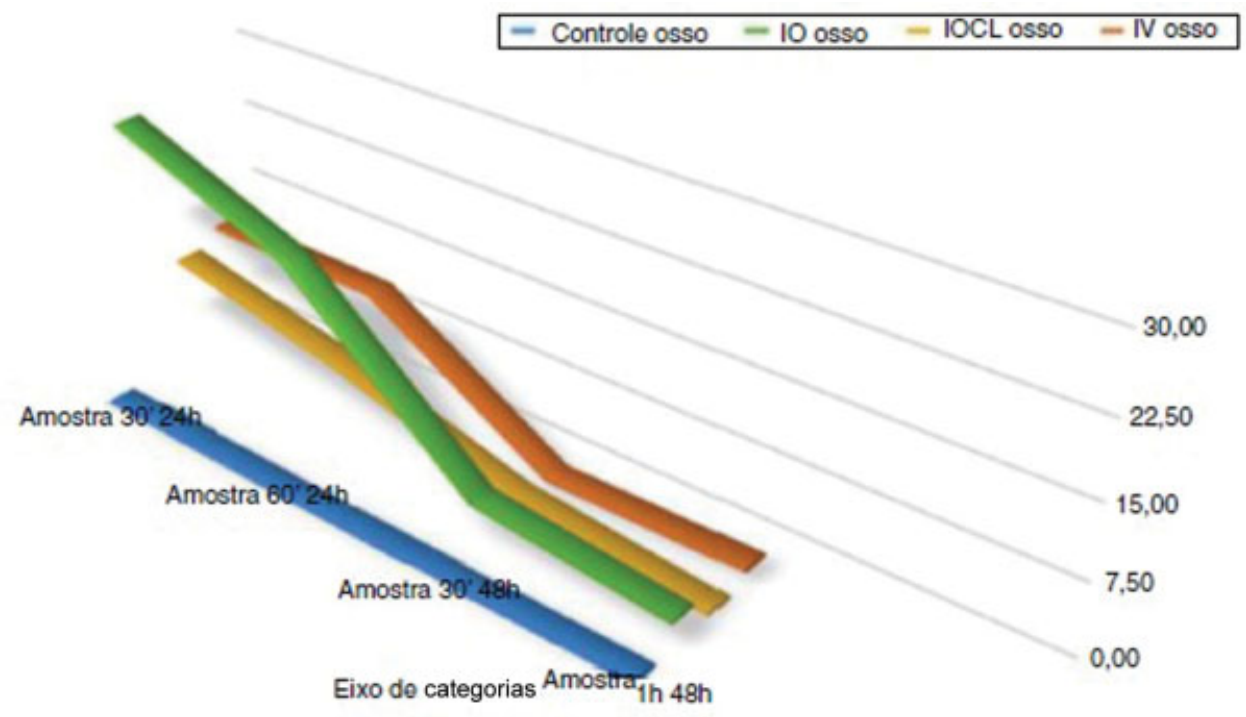

Fig. 5 Comparação do tecido ósseo entre os grupos.

próximo das amostras coletadas aos 30 minutos quando comparadas com as coletadas após 1 hora da administração da medicação.

Quando comparados os grupos de ARIO e EV, o grupo de ARIO mostrou maior inibição de crescimento bacteriano nas primeiras 24 horas após coleta de 30 minutos na pele, na cartilagem e no osso, e na coleta após 1 hora na cartilagem e no osso. A medicação na amostra do GIO perdeu efeito somente após 48 horas de incubação, e, nas amostras coletadas após 1 hora da infusão da medicação, ou seja, a medicação permaneceu mais tempo ativa do que nos outros grupos. Esse é um dos dados mais importantes obtidos no estudo, visto que o foco principal buscado é a profilaxia em cirurgias osteomusculares do joelho.

Outro dado importante analisado foi a superioridade do GIO em comparação com o GIOCL. Esse grupo apresentou o mesmo crescimento bacteriano do que o GIV, e mostrou a eficácia da ARIO e do uso de torniquete, que manteve a concentração de cefazolina alta nos tecidos locais, e disseminou pouca medicação para o joelho oposto. O GIO foi superior ao GIOCL em todos os tecidos, nas leituras após 24 horas na coleta de 30 minutos, e no tecido subcutâneo, na cartilagem e no osso, na coleta de uma hora. Na leitura após 48 horas de incubação, em ambas as coletas, a inibição bacteriana foi significativa no tecido ósseo, e mostrou que a concentração do antibiótico se manteve no GIO, enquanto no GIOCL e no GIV ela caiu.

Foram também observados alguns vieses neste trabalho. Embora tenhamos tentado usar as doses de antibióticos equivalentes e simular a situação clínica de um procedimento cirúrgico, não está claro o quanto esse modelo se aproxima da situação clínica em humanos. Além disso, embora a via IO seja relatada como tendo farmacocinética tanto para fluidos quanto para medicamentos semelhantes à administração $\mathrm{IV},{ }^{15}$ seu uso para a administração regional não é tão bem conhecido, e tem poucos trabalhos publicados.

\section{Conclusão}

Neste estudo, a ARIO pré-operatória de antibiótico profilático apresentou maior concentração local nas amostras coletadas, e resultou em uma maior inibição do crescimento bacteriano nos tecidos, em comparação com a via endovenosa. Visto que as complicações dessa prática são raras, o uso dessa via pode ser uma opção para a diminuição do risco de infecção do sítio cirúrgico nas cirurgias ortopédicas. Com isso, esse tipo de enfoque se torna cada vez mais pertinente na ortopedia e pode, posteriormente, auxiliar na mudança de protocolos de padrões de profilaxia em cirurgias articulares, com vistas à diminuição da infecção pós-operatória, considerando os benefícios para o paciente e para o sistema de saúde. Contudo, estando comprovada a eficácia do método em porcos, são necessários novos estudos experimentais em humanos, assim como o desenvolvimento de trabalhos futuros para confirmar se isso se traduz em melhor prevenção da infecção. Acreditamos que os resultados obtidos com este projeto irão contribuir para um melhor entendimento de ambas as vias estudadas e de suas eficácias, podendo abrir perspectivas para o uso do acesso em questão.

\section{Conflitos de Interesse}

Os autores declaram não haver confiitos de interesse.

\section{Referências}

1 Young SW, Zhang M, Freeman JT, Vince KG, Coleman B. Higher cefazolin concentrations with intraosseous regional prophylaxis in TKA. Clin Orthop Relat Res 2013;471(01):244-249

2 Neut D, Hendriks JG, van Horn JR, Kowalski RS, van der Mei HC, Busscher HJ. Antimicrobial efficacy of gentamicin-loaded acrylic bone cements with fusidic acid or clindamycin added. J Orthop Res 2006;24(02):291-299

3 Wellman S. Preoperative Antibiotic Dosing for Total Knee Arthroplasty: Intraosseous Versus Systemic Infusion. Principal investigator: ClinicalTrials.gov identifier: NCT02433704. Study First Received: April 10, 2015. Last Updated: November 11, 2015. Estimated Study 
Completion Date: June 2018. Available at: https://clinicaltrials.gov/ ct2/show/NCT02433704

4 Yamada K, Matsumoto K, Tokimura F, Okazaki H, Tanaka S. Are bone and serum cefazolin concentrations adequate for antimicrobial prophylaxis? Clin Orthop Relat Res 2011;469(12):3486-3494

5 Saegeman V, Lismont D, Verduyckt B, Ectors N, Stuyck J, Verhaegen J. Antimicrobial susceptibility of coagulase-negative staphylococci on tissue allografts and isolates from orthopedic patients. J Orthop Res 2007;25(04):501-507

6 Burke JF. The effective period of preventive antibiotic action in experimental incisions and dermal lesions. Surgery 1961; 50:161-168

7 Young SW, Roberts T, Johnson S, Dalton JP, Coleman B, Wiles S. Regional intraosseous administration of prophylactic antibiotics is more effective than systemic administration in a mouse model of TKA. Clin Orthop Relat Res 2015;473(11):3573-3584

8 Schurman DJ, Hirshman HP, Kajiyama G, Moser K, Burton DS. Cefazolin concentrations in bone and synovial fluid. J Bone Joint Surg Am 1978;60(03):359-362
9 Koneman EW. Diagnóstico microbiológico: texto e atlas colorido. 5a. ed. Rio de Janeiro: MEDSI; 2001

10 Murray PR, Baron JE, Pfaller AM, Tenover CF, Yolken HR, Eds. Manual of clinical microbiology. 7th ed. Washington, DC: American Society for Microbiology; 1999

11 Tocantins LM, O'neill JF, Price AH. Infusions Of Blood And Other Fluids Via The Bone Marrow In Traumatic Shock And Other Forms Of Peripheral Circulatory Failure. Ann Surg 1941;114(06):1085-1092

12 Tocantins LM. Rapid absorption of substances injected into the bone marrow. Proc Soc Exp Biol Med 1940;45(01):292-296

13 Brickman KR, Rega P, Koltz M, Guinness M. Analysis of growth plate abnormalities following intraosseous infusion through the proximal tibial epiphysis in pigs. Ann Emerg Med 1988;17(02):121-123

14 Doyon F, Evrard J, Mazas F, Hill C. Long-term results of prophylactic cefazolin versus placebo in total hip replacement. Lancet 1987;1 (8537):860

15 Craig WA. Pharmacokinetic/pharmacodynamic parameters: rationale for antibacterial dosing of mice and men. Clin Infect Dis 1998; 26(01):1-10, quiz 11-12 